\title{
Uterine Corpus Germ Cell Tumor
}

National Cancer Institute

\section{Source}

National Cancer Institute. Uterine Corpus Germ Cell Tumor. NCI Thesaurus. Code C127077.

A benign or malignant germ cell tumor that arises from the uterine corpus.

Representative examples include teratoma and yolk sac tumor. 